University of Nebraska - Lincoln

DigitalCommons@University of Nebraska - Lincoln

$11-23-1999$

\title{
Remote sensing of photosynthetic-light-use efficiency of boreal forest
}

\author{
Caroline J. Nichol \\ University of Edinburgh \\ Karl F. Huemmrich \\ NASA Goddard Space Flight Center \\ T. Andrew Black \\ University of British Columbia \\ Paul G. Jarvis \\ University of Edinburgh \\ Charles L. Walthall \\ United States Agricultural Research Service
}

See next page for additional authors

Follow this and additional works at: https://digitalcommons.unl.edu/nasapub

Part of the Physical Sciences and Mathematics Commons

Nichol, Caroline J.; Huemmrich, Karl F.; Black, T. Andrew; Jarvis, Paul G.; Walthall, Charles L.; Grace, John; and Hall, Forrest G., "Remote sensing of photosynthetic-light-use efficiency of boreal forest" (1999). NASA Publications. 12.

https://digitalcommons.unl.edu/nasapub/12

This Article is brought to you for free and open access by the National Aeronautics and Space Administration at DigitalCommons@University of Nebraska - Lincoln. It has been accepted for inclusion in NASA Publications by an authorized administrator of DigitalCommons@University of Nebraska - Lincoln. 


\section{Authors}

Caroline J. Nichol, Karl F. Huemmrich, T. Andrew Black, Paul G. Jarvis, Charles L. Walthall, John Grace, and Forrest G. Hall 


\title{
Remote sensing of photosynthetic-light-use efficiency of boreal forest
}

\author{
Caroline J. Nichol ${ }^{\mathrm{a}, *}$, Karl F. Huemmrich ${ }^{\mathrm{b}, 1}$, T. Andrew Black ${ }^{\mathrm{c}, 2}$, Paul G. Jarvis ${ }^{\mathrm{a}, 3}$, \\ Charles L. Walthall ${ }^{\mathrm{d}, 4}$, John Grace ${ }^{\mathrm{a}, 5}$, Forrest G. Hall ${ }^{\mathrm{b}, 6}$ \\ ${ }^{a}$ Institute of Ecology and Resource Management, University of Edinburgh, EH9 3JU, Scotland, UK \\ b NASA Goddard Space Flight Center, Code 923, Greenbelt, MD 20771, USA \\ ${ }^{c}$ Department of Agricultural Sciences, University of British Columbia, Vancouver, Canada V6T 1Z4 \\ ${ }^{\mathrm{d}}$ United States Agricultural Research Service, Remote Sensing Laboratory, Beltsville, MD 20707, USA
}

Received 12 April 1999; received in revised form 22 November 1999; accepted 23 November 1999

\begin{abstract}
Using a helicopter-mounted portable spectroradiometer and continuous eddy covariance data we were able to evaluate the photochemical reflectance index (PRI) as an indicator of canopy photosynthetic light-use efficiency (LUE) in four boreal forest species during the Boreal Ecosystem Atmosphere experiment (BOREAS). PRI was calculated from narrow waveband reflectance data and correlated with LUE calculated from eddy covariance data. Significant linear correlations were found between PRI and LUE when the four species were grouped together and when divided into functional type: coniferous and deciduous. Data from the helicopter-mounted spectroradiometer were then averaged to represent data generated by the Airborne Visible Infrared Imaging Spectrometer (AVIRIS). We calculated PRI from these data and relationships with canopy LUE were investigated. The relationship between PRI and LUE was weakened for deciduous species but strengthened for the coniferous species. The robust nature of this relationship suggests that relative photosynthetic rates may be derived from remotely-sensed reflectance measurements. (2000 Elsevier Science B.V. All rights reserved.
\end{abstract}

Keywords: Xanthophyll cycle; AVIRIS; Photochemical reflectance index; Eddy covariance

\footnotetext{
* Corresponding author. Tel.: +44-131-650-5744; fax: +44-131-662-0478.

E-mail addresses: caroline.nichol@ed.ac.uk (C.J. Nichol), karl.huemmrich@gsfc.nasa.gov (K.F. Huemmrich), ablack@interchange.ubc.ca (T.A. Black), pjarvis@ed.ac.uk (P.G. Jarvis), cwalthal@asrr.arsuda.gov (C.L.Walthall), jgrace@ed.ac.uk (J. Grace), fghall@ltpmail.nasa.gov (F.G. Hall).

1 Tel.: +301-286-4862; fax: +301-286-0239.

2 Tel.: +604-822-2730; fax: +604-822-8639.

3 Tel.: +44-131-650-5426; fax: +44-131-662-0478.

${ }^{4}$ Tel.: +301-504-6074; fax: +301-504-5031.

5 Tel.: +44-131-650-5400; fax: +44-131-662-0478.

6 Tel.: +301-286-2974; Fax: +301-286-0239.
}

\section{Introduction}

Remote sensing offers an important landscape and regional perspective on vegetation structure and function (Asner et al., 1998). Much remote sensing of vegetation has made use of broad band sensors to derive indices of vegetation cover, such as the normalised difference vegetation index (NDVI) (Tucker, 1979). Although NDVI often correlates well with biomass, leaf area index (LAI) and fraction of absorbed photosynthetically active radiation (FAPAR), it often fails to capture physiological processes that occur on fine temporal and spectral scales. For example, drought tolerant evergreens can undergo significant changes in photosynthetic light-use efficiency (LUE), without 
an equivalent change in NDVI (Running and Nemani, 1988). Photosynthesis can change from day to day or hour to hour depending on the response of the leaves to a naturally fluctuating environment, with no significant changes in canopy architecture or NDVI (Tenhunen et al., 1987).

Pioneering work has shown how the reflectance of leaves may contain a signal for photosynthetic efficiency, and therefore provide a new method to detect changes in photosynthesis using remote sensing. Photosynthetic LUE is defined here as $\mathrm{CO}_{2}$ uptake divided by the incident photosynthetic photon flux density (PPFD) and since the 1930s it has been known to decline at high PPFD as photosynthesis becomes light-saturated. More recently it has been found that when the photosynthetic system receives excess excitation energy from sunlight, the xanthophyll cycle is affected. The carotenoid violaxanthin is converted to zeaxanthin via de-epoxidase reactions (Yamamoto, 1979). Recent experimental work has shown a close correlation between xanthophyll pigment interconversion and the dissipation of excess energy in the pigment bed associated with photosystem II (PS II) (for reviews see Pfundel and Bilger, 1994; Demmig-Adams and Adams, 1994; Demmig-Adams et al., 1996). Recent evidence indicates that the conversion of the pigment violaxanthin to the photoprotective pigment zeaxanthin acts to lower the energy level of the lowest excited singlet state below that of chlorophyll- $a$, thus providing a sink for the excess excitation energy (Frank et al., 1994; Owens, 1996).

The interconversion of the xanthophyll cycle pigments can be detected in leaves through a change in the absorbance at 505-515 nm (Bilger et al., 1989) or the reflectance at $531 \mathrm{~nm}$ (Gamon et al., 1990, 1993). Because the pigments of the xanthophyll cycle are so closely linked to the LUE of PS II, a reflectance index that incorporates reflectance at $531 \mathrm{~nm}$ could provide a remote indicator of photosynthetic function. Gamon et al. (1990) formulated the photochemical reflectance index (PRI), incorporating reflectance at $531 \mathrm{~nm}$ (the xanthophyll cycle signal) and a reference wavelength (Gamon et al., 1992).

A number of studies beginning in the late 1980s explored the relationships between PRI and photosynthetic LUE at the leaf and small plot level. Measurements on individual leaves have demonstrated that PRI, calculated from narrow waveband data, was closely related to $\Delta F / F \mathrm{~m}^{\prime}$, a fluorescence-based indicator of PSII LUE, as well as LUE calculated from gas exchange measurements in leaves from a wide range of species (Penuelas et al., 1995). Fillela et al. (1996) and Gamon et al. (1997) have further presented evidence that PRI provided a widely applicable index of leaf LUE across species, functional types and nutrient levels.

The only canopy scale measurements that exist are on small plots $\left(\sim 2 \mathrm{~m}^{2}\right)$ and single species. Gamon et al. (1992) measured reflectance of sunflower plants with a portable spectroradiometer from a height of $4 \mathrm{~m}$ with wide-angle optics, allowing reflectance measurements over an area of diameter $1 \mathrm{~m}$ (consisting of 8-10 plants). This work showed that PRI closely tracked diurnal changes in photosynthetic LUE in control and nitrogen stressed canopies, but not in water stressed canopies that were undergoing severe wilting (Gamon et al., 1992).

Such observations suggest that measurement of reflectance by remote sensing in these spectral regions should also be useful for inferring canopy-scale LUE over regional and larger areas. However, at this time no work has been done to relate canopy PRI to LUE over areas of tens of meters. We have investigated the use of PRI as an index of LUE over contrasting canopy types. Extensive canopy reflectance and eddy covariance measurements of gas exchange were made over boreal forest during the BOREAS experiment (Boreal Ecosystem Atmosphere Study, for overview see Sellers et al., 1995) and provided the opportunity to investigate the PRI:LUE relationship over larger $\left(\sim 70 \mathrm{~m}^{2}\right)$ forested areas.

We report in this paper an evaluation of PRI as an indicator or photosynthetic LUE. We begin by describing the sites sampled in the boreal forest and the data set used, then proceed to outline the analysis approach for PRI:LUE. Finally, we present the results of this analysis and draw a number of conclusions regarding future directions.

\section{Materials and methods}

\subsection{Study sites}

The BOREAS field experiment took place during 1994 on the northern and southern edges of the Cana- 
dian boreal forest. A Northern Study Area (NSA) was located near Thomson, Manitoba, and Southern Study Area (SSA) was located near Candle Lake, Sask. (see Sellers et al., 1995b for details) and specific sub-sites within the SSA were intensively studied during the growing season. A brief outline of the sites used in this study is included here.

\subsection{Old black spruce}

The site lies in the southern mixed forest zone about $100 \mathrm{~km}$ north of Prince Albert in Sask. $\left(53^{\circ} 55^{\prime} \mathrm{N}\right.$, $105^{\circ} 5^{\prime} \mathrm{W}$, elevation $630 \mathrm{~m}$ ), and has been described by Jarvis et al. (1997). The terrain is essentially flat with pure and mixed stands of black (Picea mariana (Mill.) BSP) and white spruce (P. glauca Moench.), jack pine (Pinus banksiana Lamb.), aspen, fen and lakes. The substratum is peat overlying glacial drift with an elevated water table so the surface is generally wet. The understorey is sparse with some low shrubs reaching $\sim 1.5 \mathrm{~m}$ in height.

\subsection{Old jack pine}

The jack pine forest (Pinus banksiana Lamb.) stand grows in the SSA near Nipawin, Sask., Canada $\left(53^{\circ} 54^{\prime} \mathrm{N}, 104^{\circ} 41^{\prime} \mathrm{W}\right.$, elevation $\left.579 \mathrm{~m}\right)$ and has been described by Baldocchi et al. (1997). The landscape is relatively flat (slope $\sim 2$ and $5 \%$ ) with pure and mixed stands of black (P. mariana (Mill.) BSP) and white spruce ( $P$. glauca Moench.), aspen, jack pine and fen. The soil is a coarse textured, well drained sand. The ground was covered with an optically bright mat consisting of bearberry (Arctostaphylos uva-ursi), bog cranberry (Vaccinium vitis-idaea), and lichens (Cladina spp.).The understorey vegetation is sparse but there are isolated groups of alder (Alnus crispa).

\subsection{Old aspen}

The site is located in the SSA within Prince Albert National Park, Sask. $\left(53^{\circ} 38^{\prime} \mathrm{N}, 106^{\circ} 12^{\prime} \mathrm{W}\right.$, elevation $600 \mathrm{~m}$ ) and has been described by Hogg et al. (1997). It is an extensive, mostly pure, stand of trembling aspen (Populus tremuloides Michx.) Orthic gray luvisol with a loam texture dominates the site. Beaked hazelnut (Corylus cornutta Marsh) dominates the understorey shrub layer and is approximately $2 \mathrm{~m}$ in height. Wild rose (Rosa woodsii) and alder (A. crispa) are found in intermittently.

\subsection{Fen}

The fen study site is located in the SSA, $115 \mathrm{~km}$ northeast of Prince Albert, Sask. (53 $57^{\prime} \mathrm{N}, 105^{\circ} 57^{\prime} \mathrm{W}$, elevation $525 \mathrm{~m}$ ). The fen study site is a minerotrophic, patterned fen surrounded by black spruce (P. mariana (Mill.) BSP)) and jack pine (Pinus banksiana Lamb.) forests and has been described by Sukyer et al. (1997). Abundant herbaceous species throughout the fen included bogbean (Menyanthes trifoliata) and several sedge species (Carex and Eriophorum spp.). Dominant woody plant species are $0.5-1.5 \mathrm{~m}$ tall bog birch (Betula pumila) and widely scattered, stunted tamarack trees (Larix laricina). Mosses whilst present are not abundant in this fen.

\subsection{Canopy spectral reflectance data}

The National Aeronautics and Space Administration (NASA) Goddard Space Flight Center (GSFC)/Wallops Flight Facility (WFF) helicopterbased optical remote sensing system (Walthall et al., 1996) was deployed to acquire canopy multispectral data with a portable spectroradiometer. A spectroradiometer (model SE-590, Spectron Engineering, Denver, Colorado) was mounted on a steel rack at nadir orientation and processed to an atmospherically corrected at-surface reflectance. A $15^{\circ}$ instantaneous field of view lens (IFOV) was fitted to yield a ground resolution of $79 \mathrm{~m}$ at the $300 \mathrm{~m}$ nominal altitude. The SE-590 had a spectral range of $362.7-1122.7 \mathrm{~nm}$, with a usable range of $400-900 \mathrm{~nm}$. Data are reported at $3 \mathrm{~nm}$ intervals calculated at the centre point of a five $3 \mathrm{~nm}$ bin running average.

Data were acquired on clear days (incident PPFD $>900 \mu \mathrm{mol} \mathrm{m}^{-2} \mathrm{~s}^{-1}$ ) whilst the helicopter hovered at each site for 1-2 min for each observation (consisting of an average of 20-25 scans). Observations were made in the spring, summer and autumn (Table 1). Radiometric calibration and spectral calibration procedures were performed before and after the field season to check for changes in sensor radiometric response. The SE-590 data were corrected 
Table 1

Summary of the dates of the reflectance data acquisition with the range of temperature and solar radiation experienced during the observation periods

\begin{tabular}{|c|c|c|c|c|}
\hline Site & Instrument & Observation date & Range of temperature ${ }^{\circ} \mathrm{C}$ & $\begin{array}{l}\text { Range of solar } \\
\text { radiation } \mu \mathrm{mol} \mathrm{m}^{-2} \mathrm{~s}^{-1}\end{array}$ \\
\hline Old aspen & SE-590 & $\begin{array}{l}\text { 31-May-94 } \\
\text { 21-July-94 } \\
\text { 25-July-94 } \\
\text { 13-Sept-94 }\end{array}$ & $\begin{array}{l}17.7-18.3 \\
22.6-23.3 \\
21.5-21.7 \\
15.7-16.4\end{array}$ & $\begin{array}{r}992-1129 \\
1339-1539 \\
1343-1450 \\
1077-1216\end{array}$ \\
\hline Fen & SE-590 & $\begin{array}{l}\text { 01-June-94 } \\
\text { 06-June-94 } \\
\text { 21-July-94 } \\
\text { 13-Sept-94 }\end{array}$ & $\begin{array}{l}20.5-21.0 \\
21.2-21.2 \\
21.3-21.6 \\
12.4-12.9\end{array}$ & $\begin{array}{l}1043-1352 \\
1445-1545 \\
1222-1366 \\
1021-1117\end{array}$ \\
\hline Old jack pine & SE-590 & $\begin{array}{l}\text { 31-May-94 } \\
\text { 06-June-94 } \\
\text { 21-July-94 } \\
\text { 24-July-94 } \\
\text { 13-Sept-94 }\end{array}$ & $\begin{array}{l}15.9-16.7 \\
21.0-21.2 \\
25.4-25.7 \\
21.1-21.4 \\
18.9-19.5\end{array}$ & $\begin{array}{l}1022-1192 \\
1416-1545 \\
1397-1476 \\
1382-1498 \\
1196-1271\end{array}$ \\
\hline Old black spruce & SE-590 & $\begin{array}{l}\text { 01-June-94 } \\
\text { 06-June-94 } \\
\text { 21-July-94 } \\
\text { 23-July-94 } \\
\text { 13-Sept-94 }\end{array}$ & $\begin{array}{l}18.4-18.6 \\
20.4-20.6 \\
24.6-25.3 \\
18.5-18.9 \\
18.7-19.1\end{array}$ & $\begin{array}{l}1399-1498 \\
1361-1479 \\
1500-1579 \\
1216-1341 \\
1177-1236\end{array}$ \\
\hline
\end{tabular}

to at-surface reflectances using the $6 \mathrm{~S}$ atmospheric radiative transfer model and sun photometer data.

PRI from the SE-590 data was formulated:

$$
I_{\mathrm{PR} \mathrm{SE}-590}=\left(R_{569}-R_{529}\right) /\left(R_{569}+R_{529}\right)
$$

where $R_{529}$ indicates the reflectance centred at $529 \mathrm{~nm}$ with upper and lower band limits of 536.5 and $521.5 \mathrm{~nm}$ (coinciding with the signal of the xanthophyll cycle) and $R_{569}$ indicates the reflectance centred at the $569 \mathrm{~nm}$ waveband with upper and lower band limits of 561.5 and $576.5 \mathrm{~nm}$ (a reference waveband). This differs slightly from that used in previous studies, but still lies within the range of wavelengths considered applicable for the calculation of PRI (Gamon et al., 1993). By referencing $R_{529}$ to $R_{569}$, this index normalises for factors which include pigment content and chloroplast movement both of which can affect the $R_{529}$ signal (Gamon et al., 1993).

\subsection{A simulation of AVIRIS data}

The Airborne Visible Infrared Imaging Spectrometer (AVIRIS) (for details see Green et al., 1998) is flown aboard the NASA ER-2 aircraft at an altitude of $20 \mathrm{~km}$ and acquires data in 224 contiguous channels of the shortwave spectrum $(400-2500 \mathrm{~nm})$. It measures at a larger spatial scale than the helicopter producing a ground coverage of $\sim 120 \mathrm{~km}^{2}$ with a $20 \mathrm{~m}$ spatial resolution and spectral resolution of $10 \mathrm{~nm}$. Since this instrument uses new technology that may be amenable for measuring the status of the xanthophyll cycle (but as yet is untested) the data generated by the SE-590 were averaged to those wavebands generated by the AVIRIS instrument (waveband information supplied by Green, NASA, JPL). The SE-590 data were thus averaged to the mid-point of each band, as is standard practice with hyperspectral sensors. PRI was thus calculated:

$I_{\mathrm{PR} \text { AVIRIS }}=\left(R_{570.5}-R_{530.5}\right) /\left(R_{570.5}+R_{530.5}\right)$

where $R_{570.5}$ indicates the reflectance over the range of $566-575 \mathrm{~nm}$ and $R_{530.5}$ indicates the reflectance over the range $526-535 \mathrm{~nm}$. $R_{570.5}$ was the closest available reference waveband to that used in the computation of PRI from the helicopter data (Eq. (1)).

\subsection{Eddy covariance measurement of fluxes}

Half-hour fluxes of momentum, sensible heat, water vapour and carbon dioxide (as well as meteorological variables) were measured at all sites 
using tower-mounted, eddy covariance systems continuously from May through September of the 1994 growing season. Full details of the theory and instrument set for each site are published elsewhere. For old black spruce see (Jarvis et al., 1997; old jack pine, Baldocchi et al., 1997; old aspen, Blanken et al., 1997; fen, Sukyer et al., 1997).

\subsection{Estimates of stand photosynthesis}

The $\mathrm{CO}_{2}$ flux was partitioned into photosynthesis and respiration components by estimating daytime ecosystem respiration as functions of soil temperature. Following Goulden et al. (1997), night-time half-hour $\mathrm{CO}_{2}$ fluxes at high windspeeds (friction velocity, $u^{*}>0.2$ ) were plotted against soil temperature (at $5 \mathrm{~cm}$ ) and the usual exponential function fitted, of the form,

$A=c \mathrm{e}^{b T_{\mathrm{s}}}$

where $A$ is carbon dioxide flux, $T_{\mathrm{s}}$ is soil temperature, $c$ and $b$ are constants and $\mathrm{e}$ is the base of the natural logarithm. Daytime respiration was then calculated using this function and daytime soil temperatures. This was done for each month's night-time half-hour flux data from May until September for each of the sites (data not shown). Photosynthesis was then calculated as the daytime half-hour $\mathrm{CO}_{2}$ fluxes after the respiration component had been removed (Lloyd and Taylor, 1994). Because the helicopter overpass occurred on clear bright days (PPFD $>900 \mu \mathrm{mol} \mathrm{m}^{-2} \mathrm{~s}^{-1}$ ), the $\mathrm{CO}_{2}$ flux data for these periods were restricted to PPFD $>900 \mu \mathrm{mol} \mathrm{m}^{-2} \mathrm{~s}^{-1}$. Photosynthesis and incident PPFD were averaged above this PPFD and a daily LUE value computed from these averages according to the following:

$$
\begin{aligned}
& \text { Canopy light-use efficiency } \\
& \quad=\frac{\text { Canopy photosynthesis }}{\text { Incident photosynthetic photon flux density }}
\end{aligned}
$$

\section{Data analysis}

\subsection{Correlating PRI with LUE data}

Relationships between PRI and field measured estimates of photosynthetic LUE were investigated with linear regression analysis. This was done for the four sites sampled and then with respect to functional group. Relationships between the simulated AVIRIS data and LUE were also investigated with linear regression analysis for all species sampled and with respect to functional type.

\section{Results}

Two mean representative reflectance spectra obtained from the SE-590 spectroradiometer, each representing coniferous or deciduous forest are shown in Fig. 1 along with the two wavebands used for the calculation of PRI.

In the absence of normalisation, the reflectance at $529 \mathrm{~nm}\left(R_{529}\right)$ yielded no clear correlation with LUE for the coniferous and deciduous species together (Fig. 2A), or for the deciduous species (Fig. 2B) and coniferous species (Fig. 2C). However, after normalisation midday top canopy $\mathrm{PRI}_{\mathrm{SE}-590}$ values were significantly correlated with canopy LUE across the four species sampled $\left(R^{2}=0.64, p<0.05\right.$, Fig. $\left.3 \mathrm{~A}\right)$. The correlations were stronger when the species were divided into their functional groups. A linear relationship was apparent between PRI $\mathrm{SE}_{\mathrm{S} 90}$ and LUE for the deciduous species $\left(R^{2}=0.78, p<0.05\right.$, Fig. $\left.3 \mathrm{~B}\right)$ and coniferous species $\left(R^{2}=0.65, p<0.05\right.$, Fig. $\left.3 \mathrm{C}\right)$.

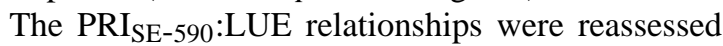
by calculating $\mathrm{PRI}_{\mathrm{SE}-590}$ using a range of reference wavelengths. Fig. 4A shows a summary of the $R^{2}$ of the relationship between $\mathrm{PRI}_{\mathrm{SE}-590}$ and LUE. The peak of this graph would be the best combination of xanthophyll wavelength and reference wavelength for the estimation of LUE. A reference wavelength of $569 \mathrm{~nm}$ produces the best relationship between PRI $\mathrm{SE}_{\mathrm{S}-50}$ and LUE. This is also the optimal reference waveband to use for the deciduous species (Fig. 4B), but for the coniferous sites, the selection of a slightly longer reference wavelength generated a stronger relationship

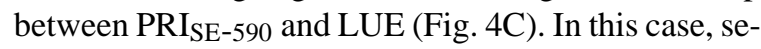
lecting a reference wavelength of $575 \mathrm{~nm}$ produced an $R^{2}$ of 0.82 in the relationship between $\mathrm{PRI}_{\mathrm{SE}-590}$ and LUE.

When the reflectance data from the SE-590 were averaged to simulate data generated by the AVIRIS instrument, scatter was introduced into the relationship between PRI AVIRIS and LUE. The PRI $_{\text {AVIRIS }}$ :LUE 


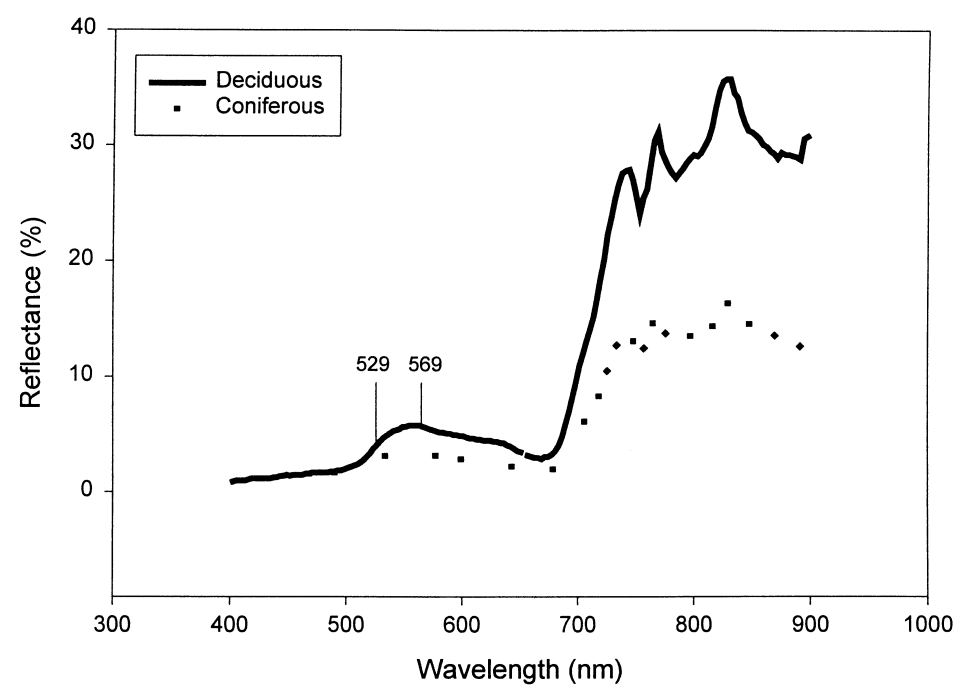

Fig. 1. Mean spectra of the coniferous and deciduous forest canopy from the BOREAS southern study area. Each curve represents the mean of 20-25 scans acquired by the helicopter mounted SE-590 spectroradiometer. Wavelengths used for PRI calculation are shown in the Figure.

relationship across the four species were significantly linearly correlated $\left(R^{2}=0.46, p<0.05\right.$, Fig. 5A). The relationship between PRI $\mathrm{AVIRIS}_{\text {and }}$ LUE was weakened within the deciduous species $\left(R^{2}=0.38, p<0.05\right.$, Fig. 5B) but strengthened within the coniferous species $\left(R^{2}=0.78, p<0.05\right.$, Fig. 5C).

\section{Discussion}

\subsection{Canopy PRI and photosynthetic LUE}

The consistent relationship between PRI $\mathrm{SE}_{590}$ and LUE for canopies sampled in full sunlight (Fig. 3A-C) supports the hypothesis that PRI $\mathrm{SE}-590$ provides a measure of PS II LUE across species and functional types. Similar observations have been made using individual leaves and small plots $(\sim 2 \mathrm{~m}$ ) (Gamon et al., 1990, 1992, 1997; Penuelas et al., 1995, 1997; Fillela et al., 1996), but this is the first time a relationship has been found between PRI and LUE over heterogeneous forest canopies.

Penuelas et al. (1995) studied the relationship between PRI and PS II LUE in plants differing in phenology, habit and photosynthetic type, and found that the slope and intercept of the PRI:LUE relationship varied between species. The lack of a single relationship in their study is not surprising. Variation may arise from the environmental growth conditions, varying anatomy, morphology and pigmentation and diverse species differences. Such factors can dramatically influence the visible reflectance, and PRI (Guyot, 1990).

The scatter in the relationship between PRI $\mathrm{SE}-590$ and LUE could be the result of several factors that can cause divergence between whole leaf assimilation and PS II LUE. These factors include the Mehler reaction, photorespiration (Harbison et al., 1990) and nitrate reduction (Bloom et al., 1989), all of which compete with carboxylation for reductant generated by electron transport. In the conditions of this study, the significant correlations between PRI $\mathrm{SE}_{\mathrm{S}} 590$ and LUE within each functional group suggest that the overall photosynthetic systems were sufficiently regulated to maintain consistent relationships between PS II processes and carboxylation.

Consistent relationships between PRI and LUE at the small plot scale $(\sim 2 \mathrm{~m})$ do not always exist. Work by Gamon et al. (1992) on sunflower canopies experiencing severe water stress showed a divergence between PRI and LUE, possibly owing to increased use of reductant by photorespiration and other processes besides carboxylation. Of the sites used in this study it is possible that a degree of water stress was experienced at the old jack pine site because of the free draining nature of the soil (Cuenca et al., 1997), and 

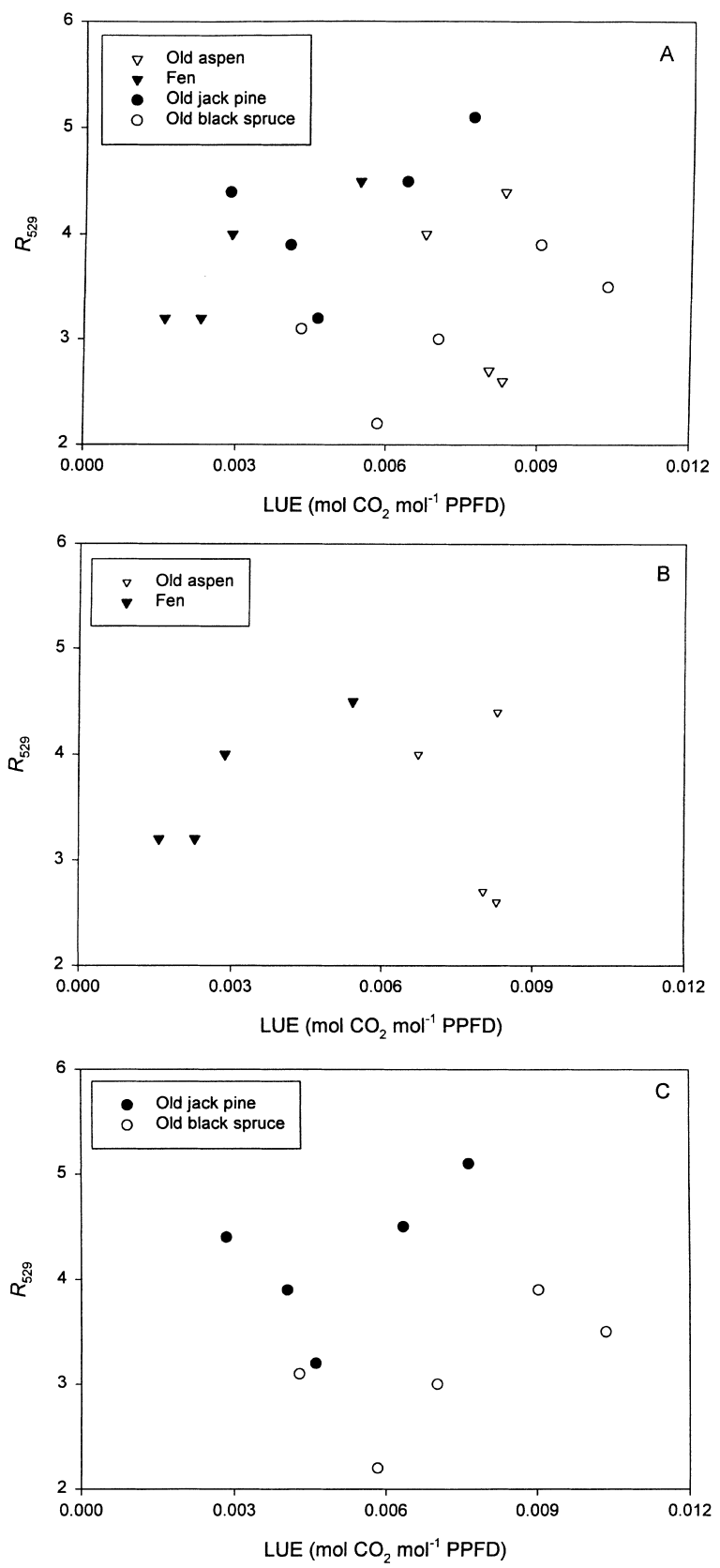

Fig. 2. Relationship between reflectance at $529 \mathrm{~nm}$ and canopy light-use efficiency (LUE). Each point is an average of 20-25 spectral scans and $4 \mathrm{~h}$ of canopy LUE data. (A) Four boreal forest species. (B) Two deciduous species. (C) Two coniferous species. Individual species are represented by the different symbols indicated.
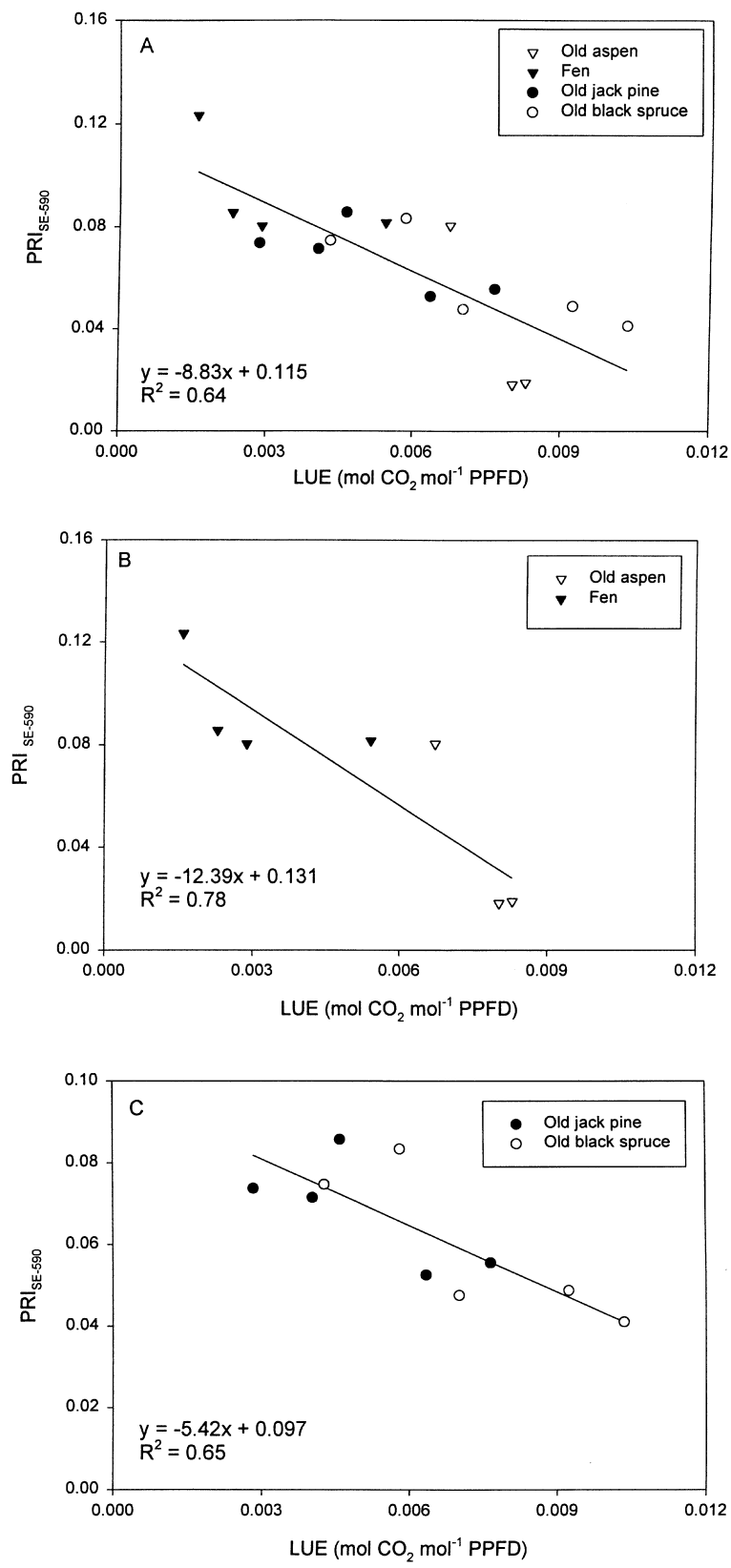

Fig. 3. Relationship between the photochemical reflectance index (PRI) and canopy light-use efficiency (LUE) for boreal forest sites sampled in full sun. Each point is an average of 20-25 spectral scans and $4 \mathrm{~h}$ of canopy LUE data. (A) Four boreal forest species. (B) Two deciduous species. (C) Two coniferous species. Individual species are represented by different symbols indicated. 

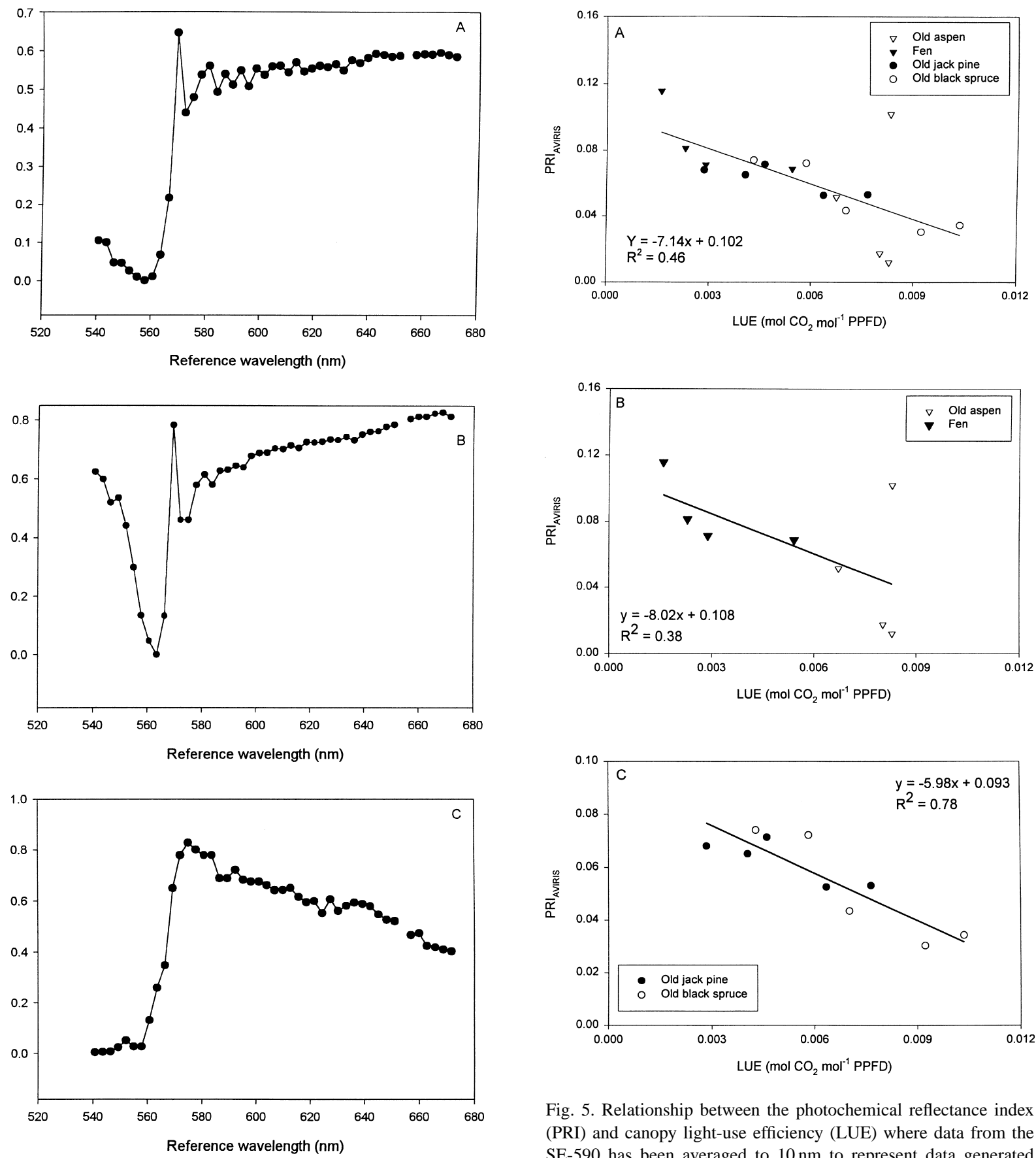

Fig. 4. A summary of the $R^{2}$ coefficients for relationship between the photochemical reflectance index (PRI) and canopy light-use efficiency (LUE). (A) Four boreal forest species. (B) Two deciduous species. (C) Two coniferous species. PRI was calculated using $R_{529}$ as the xanthophyll waveband with reference wavelengths ranging from 540 to $670 \mathrm{~nm}$, at $3 \mathrm{~nm}$ intervals.

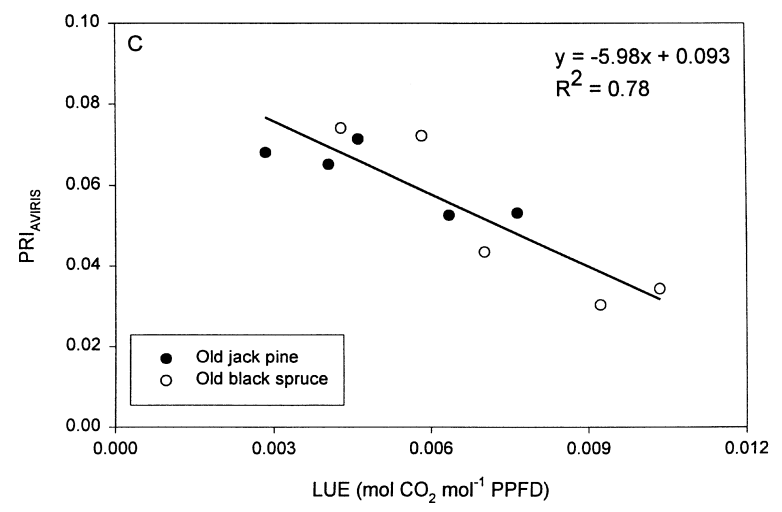

Fig. 5. Relationship between the photochemical reflectance index (PRI) and canopy light-use efficiency (LUE) where data from the SE-590 has been averaged to $10 \mathrm{~nm}$ to represent data generated by the AVIRIS sensor. (A) Four boreal forest species. (B) Two deciduous species. (C) Two coniferous species. Individual species are represented by different symbols indicated. 
some of the scatter in the PRI $\mathrm{SE}_{\mathrm{S}-590}$ :LUE relationship could be attributed to this (Baldocchi et al., 1997).

\subsection{Wavelength choice for the calculation of PRI}

The wavelength chosen to signal activity of the xanthophyll cycle differs slightly from that used in previous studies (Gamon et al., 1990, 1992, 1997; Penuelas et al., 1995; Fillela et al., 1996). However, it has been shown that the $531 \mathrm{~nm}$ 'signal' consists of two spectral components (Penuelas et al., 1995; Gamon et al., 1997). Gamon et al. (1997) found the dominance of a $545 \mathrm{~nm}$ component in low PPFD, with an appearance of a $526 \mathrm{~nm}$ component at higher PPFD. The contribution of two spectral components could explain previous reports of a non-linear relationship between PRI and LUE where samples were measured over a wide range of PPFDs (Penuelas et al., 1995). Although Gamon et al. (1990) first highlighted this, a recent paper has shown that these two spectral signals are active at different PPFDs, and can be separated in laboratory conditions (Gamon et al., 1997).

The $545 \mathrm{~nm}$ component, which was apparent in the difference spectra, is related to chloroplast conformational changes associated with the build-up of the $\mathrm{pH}$ gradient, rather than to the conversion of violaxanthin to zeaxanthin. This conclusion was based on experimental work associating the generation of the thylakoid $\mathrm{pH}$ gradient with a change in absorbance at $540 \mathrm{~nm}$ (Heber, 1969, Bilger et al., 1989, Bjorkman and Demmig-Adams, 1994) and with a corresponding reflectance change near $539 \mathrm{~nm}$ (Gamon et al., 1990). That the $545 \mathrm{~nm}$ component was initiated at lower PPFDs and progressively disappeared at higher PPFDs, suggests that it is not directly a result of xanthophyll pigment interconversion or the associated heat dissipation, but is more likely a result of light scattering changes associated with the initial build-up of the thylakoid $\mathrm{pH}$ gradient upon the sudden transition from darkness to low PPFD (Gamon et al., 1997).

The $526 \mathrm{~nm}$ component, which appears at higher PPFD, is most likely caused by spectral changes associated with the conversion of violaxanthin to zeaxanthin. This conclusion can be drawn from evidence attributing a similar absorbance change near $515 \mathrm{~nm}$ (Bilger et al., 1989; Bjorkman and Demmig-Adams, 1994) and a related reflectance change near $525 \mathrm{~nm}$ (Gamon et al., 1990), to the production of zeaxan- thin. Gamon et al. (1997) further showed that PRI, when calculated using the $526 \mathrm{~nm}$ component at high light, was more strongly correlated to LUE than PRI calculated using $531 \mathrm{~nm}$. Thus, the increased activity at PPFDs above $500 \mu \mathrm{mol} \mathrm{m} \mathrm{m}^{-2} \mathrm{~s}^{-1}$ of the $526 \mathrm{~nm}$ component is consistent with the function of xanthophyll cycle pigments as photoprotective pigments that serve to dissipate excess absorbed PPFD as heat (Demmig-Adams and Adams, 1994; Demmig-Adams et al., 1996). In the linear, quantum yield region of the photosynthetic PPFD response curve, there is no need for such energy dissipation and thus no detectable contribution of the $526 \mathrm{~nm}$ component in sun acclimated leaves. Given this information, we chose $529 \mathrm{~nm}$ to represent our xanthophyll cycle wavelength. However, because no data were acquired at low PPFD, it is not possible to confirm directly the existence of these two spectral components in this study.

We then recalculated PRI $\mathrm{SE}_{590}$ using a range of reference wavelengths and correlated it against LUE. Some surprising relationships emerged. When all the species were grouped together, the $R^{2}$ peaked at 0.645 when $569 \mathrm{~nm}$ was used as a reference. This was also the case for the deciduous species. However, the PRI $\mathrm{SE}_{\mathrm{SE}-590}$ data for the conifers were more strongly correlated with LUE when a slightly longer reference waveband of $575 \mathrm{~nm}$ was used. Gamon et al. (1992) found that any reference waveband between 539 and $570 \mathrm{~nm}$ would be suitable for the calculation of PRI $\mathrm{SE}_{590}$ and statistical correlation with LUE data. Their results however, were for a single species, rather than the four species used in this study.

\subsection{AVIRIS data and photosynthetic light-use efficiency}

The differences in the relationships between PRI and LUE from the helicopter data, as opposed to the AVIRIS simulation, suggest that the $10 \mathrm{~nm}$ resolution is not too broad to detect this spectral signal but does introduce scatter. This could present significant difficulty in extending the use of PRI to landscape scales as few sensors have the capability of measuring large areas at a resolution of less than $5 \mathrm{~nm}$. However, when the spectra are represented as difference spectra, the width of the dip representative of the 'xanthophyll' signal appears to be wider than $10 \mathrm{~nm}$ (Gamon et al., 1990, 1992; Fillela et al., 1996), and this would 
suggest that a $10 \mathrm{~nm}$ resolution should be appropriate for detecting changes in the xanthophyll cycle. Future work using AVIRIS data for PRI applications will confirm its utility for the estimation of canopy scale LUE.

\subsection{Effects of background reflectance on PRI}

The effective use of periodic remotely-sensed observations in landscape process studies depends on stable estimation of diurnally integrated conditions (Goward and Huemmrich, 1992). It has been widely documented that the reflectance measured from forest sites may vary with solar illumination angle, viewing angle, understorey or background reflectance and atmospheric effects, as well as intrinsic canopy parameters such as phytomass and leaf area index of the dominant species (Kimes, 1980; Ranson et al., 1986; Huete, 1987; Guyot, 1990; Goward and Huemmrich, 1992). Although the spectral data used in this study were acquired from a nadir orientation during conditions of highest possible solar elevation (approximately $40-60^{\circ}$ ), which would have minimised unstable calculations of PRI, a full sensitivity analysis of the PRI:LUE relationship is warranted and a companion paper will focus on these issues.

\section{Conclusions}

We have demonstrated that PRI $\mathrm{SE}_{\text {-590 }}$ can serve as an index of photosynthetic LUE over heterogeneous forest canopies. These results extend beyond earlier studies using individual leaves (Gamon et al., 1992; Penuelas et al., 1995; Fillela et al., 1996) by showing that this index is well suited to sampling areas of $\sim 70 \mathrm{~m}^{2}$ in contrasting ecosystems at high PPFD. Consequently, it should be possible to derive methods of remotely estimating relative photosynthetic rates based on reflectance in the $529 \mathrm{~nm}$ spectral region.

Our simulation of AVIRIS data shows that the resolution of this sensor is not too coarse to detect the fine spectral signal generated by the xanthophyll cycle, although it is degraded more at this resolution. Thus we propose that the application at the landscape and larger scales will require a more rigorous test of the use of AVIRIS data as well as the use of radiative transfer and geometric models, such as SAIL (Scattering from Arbitrarily Inclined Leaves) (Verhoef, 1984) and GeoSail (Huemmrich, 1995) to scale PRI and LUE to whole landscapes.

Improvement in the accuracy of scaling processes such as photosynthetic LUE will continue to be pivotal for the development of physiological ecology and global change research. As new perspectives and methods for scaling ecological function from local to global levels continues to evolve (e.g., via micrometeorological towers, remote sensing and modeling), our understanding of how functional variables scale across ecological levels must keep pace. Without this synergy, our ability to resolve important issues such as sources and sinks of $\mathrm{CO}_{2}$ will be impaired.

\section{Acknowledgements}

This work was supported by awards to CJN from the UK's Natural Environmental Research Council and a National Aeronautics and Space Administration, Planetary Biology Internship (NASA-PBI), 1998. Eddy correlation fluxes at the old jack pine site were collected by Dennis Baldocchi, Atmospheric Turbulence and Diffusion Division, NOAA, at the fen site by Shashi Verma, University of Nebraska and at the Old Aspen site fluxes were measured by a team consisting of researchers from the Atmospheric Environment Service, Downsview, Ontario and the University of British Columbia, the latter supported by a Collaborative Special Project Grant from the Natural Science and Engineering Research Council of Canada. The 1994 AVIRIS waveband data was provided by Robert Green, NASA Jet Propulsion Lab, California.

\section{References}

Asner, G.P., Wessman, C.A., Schimel, D.S., 1998. Heterogeneity of savanna canopy structure and function from imaging spectroscopy and inverse modelling. Ecol. Applications 8 (4), 1022-1036.

Baldocchi, D.D., Vogel, C.A., Hall, B., 1997. Seasonal variation of energy and water vapour exchange rates above and below a boreal jack pine forest canopy. J. Geophys. Res. 102 (D24), 28,939-28,951.

Bilger, W., Bjorkman, O., Thayer, S.S., 1989. Light induced spectral absorbance changes in relation to photosynthesis and 
the expoxidation state of xanthophyll cycle components in cotton leaves. Plant Physiol. 91, 542-551.

Bjorkman, O., Demmig-Adams, B., 1994. Regulation of photosynthetic light energy capture, conversion and dissipation in leaves of higher plants. In: Schulze, E.-D., Caldwell, M.M. (Eds.), Ecophysiology of Photosynthesis, Ecological Studies 100. Springer, Berlin, Heidelbeig, New York, pp. 17-47.

Blanken, P.D., Black, T.A., Yang, P.C., den Hartog, G., Neumann, H.H., Nesic, M.D.,. Novak, R., Staebler, R., Lee, X., 1997. Energy balance and canopy conductance of a boreal aspen forest: partitioning overstorey and understorey components. J. Geophys. Res. 102: 28, 915-28, 927.

Bloom, A.J., Calswell, R.M., Finazzo, J., Warner, R.L., Weissbart, J., 1989. Oxygen and carbon dioxide fluxes from barley shoots depends on nitrate assimilation. Plant Physiol. 91, 352-356.

Cuenca, R.H., Stangel, D.E., Kelley, S.F., 1997. Soil water balance in a Boreal forest. J. Geophys. Res. 102 (D24), 29,935-29,365.

Demmig-Adams, B., Gilmore, A.M., Adams-III, W.W., 1996. In vivo functions of carotenoids in higher plants. FASEB J. 10, 403-412.

Demmig-Adams, B., Adams, B., 1994. The role of xanthophyll cycle carotenoids in the protection of photosynthesis. Trends in Plant Sci. 1, 21-26.

Fillela, I., Amaro, J.L., Penuelas, J., 1996. Relationship between photosynthetic radiation-use efficiency of barley canopies and the photochemical reflectance index (PRI). Physiol. Plantarum 96, 211-216.

Frank, H.A., Cua, A., Chynwat, V., Young, A., Gosztola, D., Wasielewski, M.R., 1994. Photophysics of the carotenoids associated with the xanthophyll cycle in photosynthesis. Photosynthesis Res. 41, 389-395.

Gamon, J.A., Field, C.B., Bilger, W., Bjorkman, O., Freeden, A., Penuelas, J., 1990. Remote sensing of the xanthophyll cycle and chlorophyll fluorescence in sunflower leaves and canopies. Oecologia 85, 1-7.

Gamon, J.A., Fillela, I., Penuelas, J., 1993. The dynamic 531 nanometer $\Delta$ reflectance signal: a survey of 20 angiosperm species. Current Topics in Plant Physiol. 8, 172-177.

Gamon, J.A., Penuelas, J., Field, C.B., 1992. A narrow waveband spectral index that tracks diurnal changes in photosynthetic efficiency. Remote Sensing of Environ. 41, 35-44.

Gamon, J.A., Serrano, L., Surfus, J.S., 1997. The photochemical reflectance index: an optical indicator of photosynthetic radiation use efficiency across species, functional types, and nutrient levels. Oecologia 112, 492-501.

Goulden, M.L., Daube, B.C., Fan, S.M., Sutton, A., Bazzaz, J.W., Munger, S.C. and Wofsy S.C., 1997. Physiological responses of a black spruce forest to weather (BOREAS Special Issue). J. Geophys. Res. 102 (D24), 28,987-28,966.

Goward, S.N., Huemmrich, K.F., 1992. Vegetation canopy PAR absorptance and the normalised difference vegetation index: an assessment using the SAIL model. Remote Sensing of Environ. 39, 119-140.

Green, R.O., Sarture, C.M., Chrien, T.G., Aronsson, M., Chippendale, B.J., Faust, J.A., Pavri, B.E., Chovit, C.J., Solis, M., Olah, M.R., Williams, O., 1998. Imaging Spectroscopy and the Airborne Visible/Imaging Spectroradiometer (AVIRIS). Remote Sensing of Environ. 65, 227-248.
Guyot, G., 1990. Optical properties of vegetation canopies. In: Steven, M.D,. Clark, J.A., (Eds.), Applications of Remote Sensing in Agriculture. Butterworths, London, pp. 19-44.

Harbison, J., Genty, B., Baker, N.R., 1990. The relationship between $\mathrm{CO}_{2}$ assimilation and electron transport in leaves. Photosynthesis Res. 25, 213-224.

Heber, U., 1969. Conformational changes of chloroplasts induced by illumination of leaves in vivo. Biochim. Biophys. Acta. 180, 302-319.

Hogg, E.H., Black, T.A., den Hartog, G., Neumann, H.H., Zimmerman, R, Hurdle, P., Blanken, P.D., Nesic, Z., Yang, P.C., Staebler, R.M., McDonald, K.C., Oren, R., 1997. A comparison of sap flow and eddy fluxes of water vapour from a boreal deciduous forest (BOREAS Special Issue). J. Geophys. Res. 102 (D24), 28,929-28,937.

Huemmrich, K.F., 1995. An analysis of remote sensing of the fraction of absorbed photosynthetically active radiation in forest canopies. Ph.D. Thesis, University of Maryland, USA.

Huete, A.R., 1987. Soil and sun angle interactions on partial canopy spectra. Int. J. Remote Sensing 8 (9), 1307-1317.

Jarvis, P.G., Massheder, J.M., Hale, S.E., Moncrieff, J.B., Rayment, M.B., Scott, S.L., 1997. Seasonal variation of carbon dioxide, water vapour and energy exchanges of a boreal black spruce forest. J. Geophys. Res. 102 (D24), 28,953-28,966.

Kimes, D.S., 1980. Vegetation Reflectance as a function of Solar Zenith Angle. Photogrammic Eng. Remote Sensing 46 (12), 1563-1573.

Lloyd, J.L., Taylor, J.A., 1994. On the temperature dependence of soil respiration. Func. Ecol. 8, 315-323.

Owens, T.G., 1996. Processing of Excitation Energy by Antenna Pigments. In: Neil Baker (Ed.), Photosynthesis and the Environment. Kluwer Academic Publishers, NL, pp. 1-23.

Penuelas, J., Filella, I., Gamon, J.A., 1995. Assessment of the photosynthetic radiation use efficiency with spectral reflectance. New Phytol. 131, 291-296.

Penuelas, J., Llusia, J., Pinol, J., Fillela, I., 1997. Photochemical reflectance index and leaf photosynthetic radiation-useefficiency assessment in Mediterranean trees. Int. J. Remote Sensing 18 (13), 2863-2868.

Pfundel, E., Bilger, W., 1994. Regulation and possible function of the violaxanthin cycle. Photosynthesis Res. 42, 89-109.

Ranson, K.J., Daughtry, C.S.T., Biehl, L.L., 1986. Sun angle, view angle, and background effects on spectral response of simulated balsam fir canopies. Photogrammic Eng. Remote Sensing 52 (5), 649-658.

Running, S.R., Nemani, R.R., 1988. Relating seasonal patterns of the AVHRR vegetation index to simulated photosynthesis and transpiration of forests in different climates. Remote Sensing of Environ. 24, 347-367.

Sellers, P.J., Hall, F.G., Margolis, H., Kelly, B., Baldocchi, D., den Hartog, G., Cihlar, J., Ryan, M., Goodison, B., Crill, P., Ranson, J., Lettenmaier, D., Wickland, D., 1995. The Boreal-Ecosystem-Atmosphere-Study (BOREAS): an overview and early results from the 1994 field year. Bull. Am. Meteorol. Soc. 76 (9), 1549-1577.

Sukyer, A.E., Verma, S.B., Arkebauer, T.J., 1997. Season-long measurement of carbon dioxide exchange in a boreal fen. J. Geophys. Res. 102 (D24): 29,021-29,028. 
Tenhunen, J.D., Catarino, F.M., Lange, O.L., Oechel, W.C. (Eds.), 1987. Plant Responses to Stress. Functional Analysis in Mediterranean Ecosystems. Springer, Berlin.

Tucker, C.J., 1979. Red and photographic infrared linear combinations for monitoring vegetation. Remote Sensing of Environ. 8, 127-150.

Walthall, C., Williams, D.L., Markham, B., Kalshoven, J., Nelson, R., 1996. Development and present configuration of the NASA GSFC/WFF helicopter based remote sensing system. Int. Geosci. Remote Sensing Symp., Lincoln, NE.

Verhoef, W., 1984. Light scattering by leaf layers with application to canopy reflectance modelling: the SAIL model. Remote Sensing of Environ. 16, 125-141.

Yamamoto, H.Y., 1979. Biochemistry of the violaxanthin cycle in higher plants. Pure Appl. Chem. 51, 639-648. 